\title{
Determining sex by bone volume from 3D images: discriminating analysis of the tali and radii in a contemporary Spanish reference collection.
}

Ruiz Mediavilla, Elena, Perea Pérez, Bernardo, Labajo González, Elena, Sánchez Sánchez, José Antonio, Santiago Sáez, Andrés y Dorado Fernández, Enrique.

Cita:

Ruiz Mediavilla, Elena, Perea Pérez, Bernardo, Labajo González, Elena, Sánchez Sánchez, José Antonio, Santiago Sáez, Andrés y Dorado Fernández, Enrique (2012). Determining sex by bone volume from 3D images: discriminating analysis of the tali and radii in a contemporary Spanish reference collection. Int J Legal Med, 126 (4), 623-631. Dirección estable: https://www.aacademica.org/elenalabajogonzalez/26 ARK: https://n2t.net/ark:/13683/pcQr/6DN

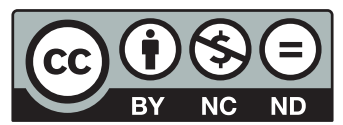




\title{
Determining sex by bone volume from 3D images: discriminating analysis of the tali and radii in a contemporary Spanish reference collection
}

\author{
Elena Ruiz Mediavilla • Bernardo Perea Pérez • \\ Elena Labajo González • \\ José Antonio Sánchez Sánchez • Andrés Santiago Sáez • \\ Enrique Dorado Fernández
}

Received: 28 January 2012 / Accepted: 2 May 2012

(C) Springer-Verlag 2012

\begin{abstract}
The discriminant power of bone volume for determining sex has not been possible to determine due to the difficulty in its calculation. At present, new advancements based on 3D technology make it possible to reproduce the bone digitally and calculate its volume using computerized tools, which opens up a new window to ascertaining the discriminant power of this variable. With this objective in mind, the tali and radii of 101 individuals (48 males and 53 females) of a contemporary Spanish reference collection (twentieth century) (EML 1) were scanned using the Picza 3D Laser Scanner. Calculated for the tali were total volume, the volume of the posterior region, which includes the posterior calcaneal facet and other three volumes of the anterior region. Calculated for the radius were total volume, volume of the radius head, volume of the diaphysis, and volume of the distal end. The data are presented for all of the variables, distinguishing between the right and left side. The data were processed using the statistical program PASW Statistics 18 , thereby obtaining classification functions for sex which accurately classify $90.9 \%$ of tali and $93.9 \%$ of radii on the basis of their total left and right volume, respectively. Studying the volume in different regions of the bone shows that the diaphysis of the right radius possesses a high
\end{abstract}

Electronic supplementary material The online version of this article (doi:10.1007/s00414-012-0715-5) contains supplementary material, which is available to authorized users.

E. Ruiz Mediavilla • B. Perea Pérez • E. Labajo González $(\triangle) \cdot$ J. A. Sánchez Sánchez • A. Santiago Sáez • E. Dorado Fernández Escuela de Medicina Legal/Departamento de Toxicología y Legislación Sanitaria/Facultad de Medicina (Pab. 7), Universidad Complutense de Madrid,

Ciudad Universitaria S/N,

28040 Madrid, Spain

e-mail: elabajo@med.ucm.es level of discriminant power, offering classification functions which accurately classify $96.9 \%$ of the sample. The validation test performed on a sample of 20 individuals from another contemporary Spanish reference collection (EML 2) confirms the high discriminant power of the volume obtaining an accurate classification rate of $80-95 \%$ depending on the variable studied.

Keywords Talus $\cdot$ Radius $\cdot$ Volume $\cdot 3$ D scanner . Discriminant power

One of the main objectives of forensic anthropology is to determine the sex of bone remains which are subjected to study. Because bones are not always available which provide a high discriminant power, such as the pelvis or skull, new studies must be performed on the postcranial skeleton in an attempt to find variables which make it possible to determine sex with a greater rate of reliability. It is recommendable to perform such studies on reference collections in which the sex of the individuals is known. The bones chosen to start this investigation have been the tali and radii. The election has been based on the size and morphology of the bones thinking of the characteristics of the $3 \mathrm{D}$ scanner and the difficulties that could appear during the scan process because of the irregular morphology of the bone.

The reports published to date offer classification functions based on linear measurements for these two bones and for different populations [1-5]. The discriminant power of weight on the talus has also been studied but has proven not to be very reliable in determining sex [6]. Cranium volume, on the other hand, has undergone widespread study, using a varied methodology [7-14], with an emphasis on the interest in establishing differences between the many species of 
hominids $[15,16]$, and on variability within populations [17]. More recently, there was a notable study of correlations between the different volumes of cranial regions and face size [18], as well as studies on differences in volumes among different regions of the brain based on sex [19]. As for the bone volume studies on the postcranial skeleton, the purpose with which they have been performed is variable, with an emphasis on the interest in clinical practice to observe anomalies during growth [20] or to observe volume differences in the articulation cartilage based on sex [21, 22]. Also important are the studies which include new methodologies to evaluate the discriminant power of certain bones and regions; methods based on digital radiometric studies [23], lateral cephalometric studies [24], or morphometric analysis of digital photographs [25]. In terms of the specific analytical studies on sexual dimorphism using 3D imaging, one of the most noteworthy is the work by Sholts et al. (2010) completed on craniums [26], while on the postcranial skeleton the most notable are the studies based on geometric morphometrics [27, 28]. In accordance with these last lines of research based on 3D imaging and due to the lack of studies which quantify the discriminant power of bone volume in determining sex on the basis of bones in the postcranial skeleton, a first study on the talus and radius bones was performed by calculating their volume in a sample taken from a contemporary Spanish reference collection (twentieth century) (EML 1).

Volume is a scalar magnitude defined as the space occupied by a body. There are different methods to calculate volume, but those that could be used for this study are the ones which can be applied to irregular objects because both the radius and the talus possess an irregular morphology. Under such conditions, one of the methods which may be used is to calculate their volume by fluid displacement. This method is based on Archimedes' principle, which establishes that if a body is partially or fully submerged in a fluid, the fluid exerts a force up towards the body which is equal to the weight of the fluid displaced by the body [29]. When the bone is introduced into a graduated vessel containing water, the increase in the level of the liquid would make it possible to determine the object's volume by subtraction. The disadvantage in using this method on bone is that, because it is porous, the bone absorbs a part of the water, and there would be an increase in inaccuracy when calculating the volume because, in addition to the displaced volume, it would be necessary to bear in mind the volume of water absorbed by the bone. In addition to all of the aforementioned difficulties is the limitation of the vessel's volumetric scale. At present, considering the possibility of performing 3D scanning of bone and taking advantage of the tools offered by 3D programs, which include the calculation of volume, three-dimensional scanning was performed on the whole sample of tali and radii originating from a contemporary Spanish reference collection (EML 1), thereby making it possible to calculate the volume of $3 \mathrm{D}$ reproductions. On the basis of these 3D reproductions, it is not only possible to calculate the total volume of the bone but also to calculate the volume of certain anatomical regions, with the ability to study the extent of their sexual dimorphism. Not always is it possible to recover the bone on a good state of preservation, and some parts could be missed so having classification functions based on certain regions could be useful to determine sex. Also calculated were the volumes of the radius head, the diaphysis and its distal end, whereas three volumes of the anterior region were obtained in the talus, as well as the volume of the posterior region. The election of the regions has been based on the facility to identify and connect the points to perform the divisions on the image.

\section{Sample}

The study sample originates from a contemporary Spanish reference collection (twentieth century; EML 1) of the School of Legal Medicine of Madrid (UCM) made up of 130 individuals born between the years 1881 and 1973 in different Spanish regions and died between the years 1975 and 1985. The distribution of the sample by sex and side is shown in Table 1. Of these 130 individuals, the tali of 98 individuals (47 males and 51 females) were recovered, as well as the radii of 77 individuals (38 males and 39 females). A total of 179 tali (81 paired right and left, 10 unpaired right, and 7 unpaired left) and a total of 127 radii (50 paired right and left, 16 unpaired right, and 11 unpaired left) were 3D scanned. The study sample only includes those bones whose sex is known and which are in a good state of preservation. Those which are altered, whether due to taphonomic or pathological processes, were not included in the study. The number of radii is lower than the tali because several of them were excluded due to the bad state of preservation of the radius head.

Table 1 Distribution of the tali and radii sample

$M$ number of males, $F$ number of females

\begin{tabular}{lrrrrr}
\hline & \multicolumn{2}{c}{ Tali } & & \multicolumn{2}{c}{ Radii } \\
\cline { 2 - 3 } \cline { 5 - 6 } & $M$ & $F$ & & $M$ & $F$ \\
\hline Paired R-L & 38 & 43 & & 24 & 26 \\
Unpaired R & 7 & 3 & 8 & 8 \\
Unpaired L & 2 & 5 & 6 & 5 \\
Total & 47 & 51 & 38 & 39 \\
\hline
\end{tabular}




\section{Methodology}

The sample was scanned with a PICZA 3D Laser Scanner (made by Roland). It is a closed scanner $(528 \times 431 \times$ $742 \mathrm{~mm}$ ) with a rotating platform inside, which is accessed by way of a front door. The item to be scanned is placed on the platform, and a $600-700-\mathrm{nm}$ wave laser is projected from the right side. The program that comes with this scanner is Dr.Picza3, in which the different orientations are displayed. Depending on the shape of the bone, the rotating scans are combined with the slice scans so as to be able to scan the bone in its entirety. The rotating scans are produced by the complete rotation of the platform where the item is placed, while the laser reads the surface of the object from the bottom to the top. On the slice scans, the platform realizes a slight movement which only allows scanning the part of the object which is in front of the laser. The desired distance between points must be selected within the resolution offered by the scanner. For the case at hand, the range is from 0.2 to $1 \mathrm{~mm}$. The lesser the distance, the greater the precision the image will have and the longer the scanning time will be. For the study sample in this study, a distance between points of $0.4 \mathrm{~mm}$ was selected because this was considered to be the optimal option in terms of quality/time. The time needed to scan a talus ranges from 30 to $40 \mathrm{~min}$, and for a radius from 60 to $90 \mathrm{~min}$. In order to scan the talus, three scans were completed. In the first, the talus was placed in a vertical position, with the head oriented towards the platform, and a rotating scan was performed which made it possible to image nearly the entire surface of the bone. In the second scan, the talus was placed with its medial surface resting on the platform and the base of the talus oriented towards the laser. This made it possible to scan those areas which were not visible in the prior scan. Last of all, a slice scan was performed without changing the preceding orientation in order to obtain an extra orientation of the inferior part of the talus, due to the fact that it is especially irregular. The product of each of the scans is a point cloud (Fig. 1).

No rotating scans were performed on the radius because, due to the triangular cross section of the diaphysis, shadows were created as the laser acted over the crest, and therefore, the choice was made to perform four slice scans, placing the bone in a vertical position, supporting it on the distal epiphysis, and turning the bone $90^{\circ}$ to the right in each new orientation. By doing this, nearly all of the bone is scanned, with the exception of the upper part of the proximal epiphysis and the lower part of the distal epiphysis, the reproductions of which are obtained by performing a slice scan of each.

The different orientations obtained (Figs. 2 and 4) were merged using the program Pixform to obtain a complete image of the bone (Figs. 3, 4, and 5). To merge two orientations is necessary to find three points in common

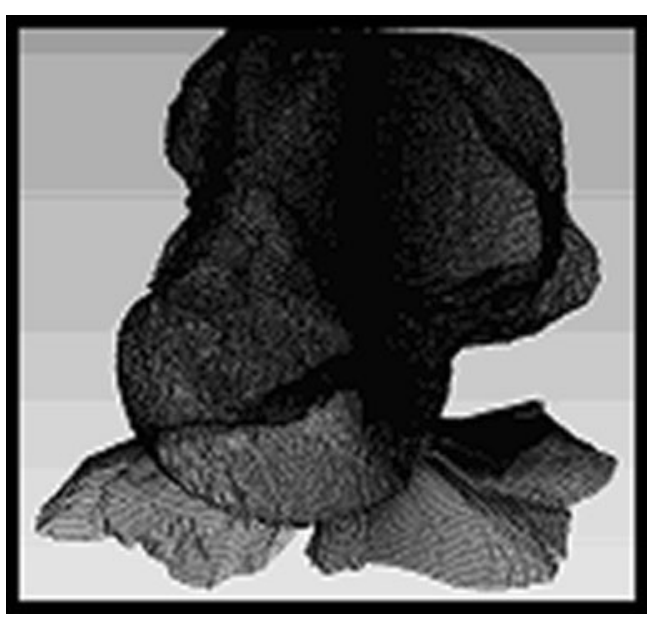

Fig. 1 Point cloud of the talus

between them. Once the merge is done, the program offers an evaluation of the result: bad, good, or excellent; evaluations worst than excellent are not accepted, and the merge has to be repeated in these cases. The complete image was then processed using the program Geomagic v10 to eliminate dirt, fill in holes, smooth the surface and, last of all, calculate the volume. The entire process was repeated on a sample of 20 tali and 20 radii to calculate the total volume of the new images and compare the results with the first ones. A paired $t$ test was performed to know the variation between the two volumes to study possible variations produced during the merging process and the image treatment.

Once the image was processed, the total volume and the volume of each of the selected anatomical regions were calculated, and a database was created using the statistical program PASW Statistics 18, including a record of the sex and volumes of each of the bones. For each individual, the right and left bone volumes are included, provided that both were existing in the collection. In order to determine whether there are areas in the bone which are more discriminant than others, and for those cases in which the bone is incomplete, the volume of certain anatomical regions of the bone

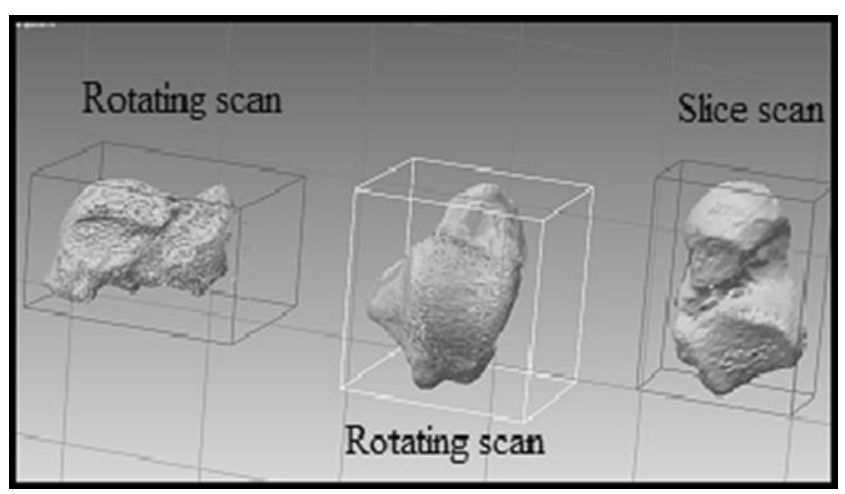

Fig. 2 Orientations of rotating and slice scans of the talus 


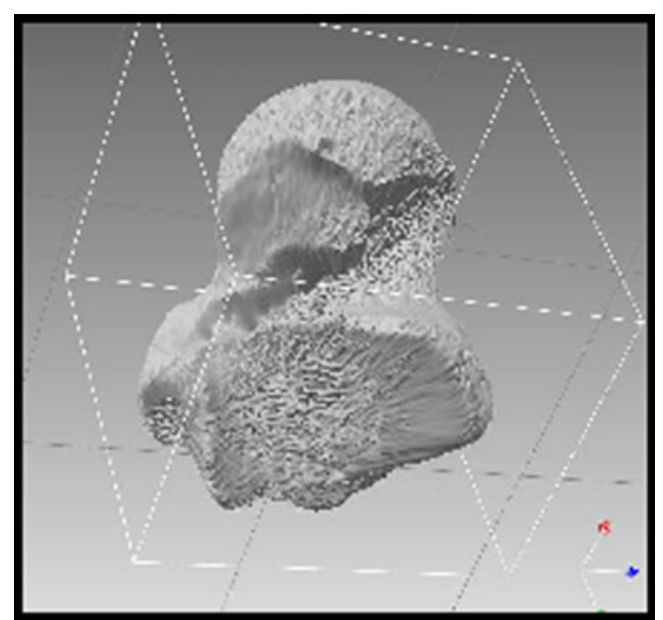

Fig. 3 Assembled orientations of the talus

has been calculated. The program tool selected to accomplish that objective was "compute volume to plane," and the option chosen to align the plane was the line. The image is divided into two by one plane, and the volume of each of the plane's divisions is calculated.

In the case of the talus, the first volume in the anterior region (anterior volume 1) was obtained by positioning the bone in a superior view and drawing a plane ahead of the facies malleolaris medialis (point 2 Fig. 6 in the Electronic supplementary materials (ESM)], and ahead of the anterior distal edge of the trochlea of the talus (point 1 Fig. 6 in the ESM). Both points always positioned on the talus neck. The volume of the superior plane's division is the one considered (Fig. 7 in the ESM).

The second volume of the anterior region (anterior volume 2) was calculated by positioning the bone in an inferior view and drawing a plane from the distal end of the facies articularis navicularis (point 2 Fig. 8 in the ESM) to the most posterior end of the medial calcaneal facet (point 1 Fig. 9 in the ESM), passing above the medial tubercle. The volume of the superior plane's division is the one considered (Fig. 10 in the ESM).

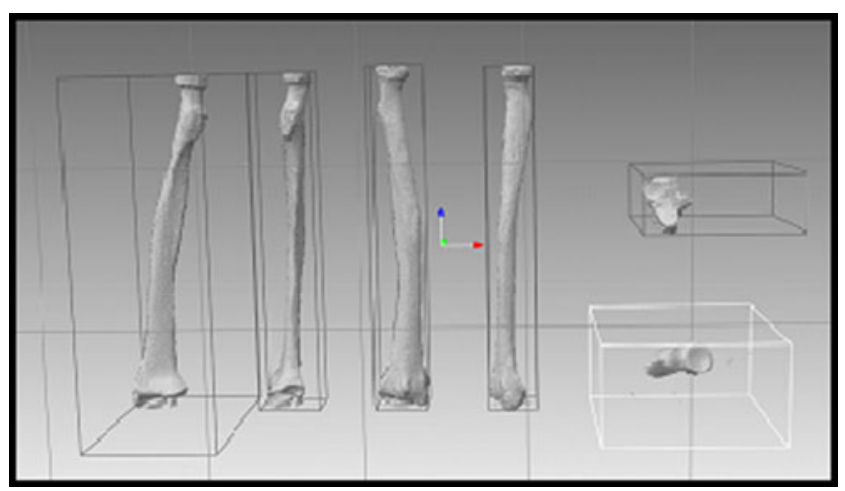

Fig. 4 Slice orientations of the radius

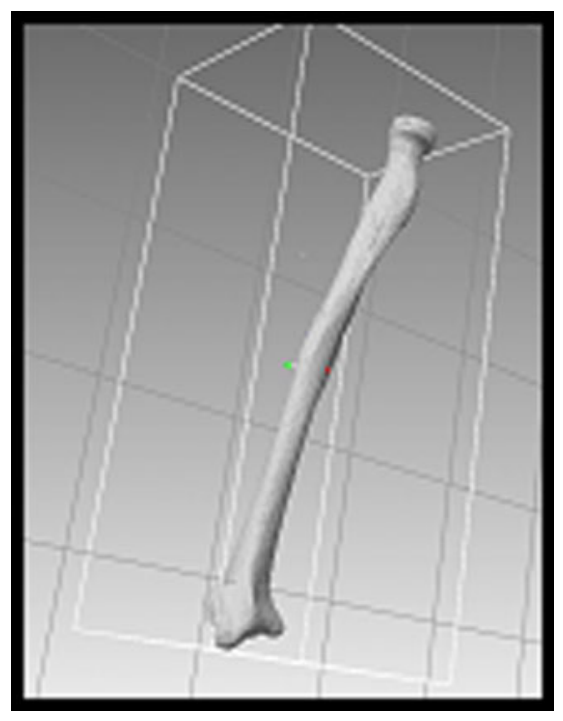

Fig. 5 Assembled orientations of the radius

The third volume of the anterior region (anterior volume 3) was calculated by positioning the bone in an inferior view and drawing a plane from the distal end of the facies articularis navicularis (point 2 Fig. 8 in the ESM) at its medial end (point 1 Fig. 11 in the ESM). The volume of the superior plane's division is the one considered (Fig. 12 in the ESM).

The volume of the posterior region of the talus was calculated by positioning the bone in an inferior view and drawing a plane from the most anterior point of the posterior calcaneal facet (point 1 Fig. 13 in the ESM) to the most anterior point of the medial tubercle (point 2 Fig. 13 in the ESM). The volume of the inferior plane's division is the one considered (Fig. 14 in the ESM).

For the radius, the volume of the head was calculated by positioning the bone in a lateral position and drawing a plane connecting the most lateral inferior points of the head (point 1 and 2 Fig. 15 in the ESM). The volume of the superior plane's division is the one considered (Fig. 16 in the ESM).

The volume of the distal end was calculated by positioning the bone in a lateral position and drawing a plane from the point where the lateral and distal prolongation of the radius begins (point 1 Fig. 17 in the ESM) to a point positioned at the same height but at the opposite side of the diaphysis (point 2 Fig. 17 in the ESM). The volume of the inferior plane's division is the one considered (Fig. 18 in the ESM). The volume of the diaphysis is obtained by calculating the difference between the total volume and the volumes of the radius head and distal end.

The volumes of the different anatomical regions were calculated twice with an interval of time of 2 months between measures. A paired $t$ test was performed to verify if there were statistically significant differences between the 
two measures to confirm they were taken correctly. The divisions were repeated twice (with an interval of time of 1 week) on a sample of 20 tali and 20 radii by a second observer, and a paired $t$ test was performed to study the variation between the two measures. The mean of the two measures was calculated, and a paired $t$ test was performed to study the variation between observers.

Using the data obtained, a descriptive statistic was created to ascertain the mean values of each of the variables. A Kolmogórov-Smirnov test was performed to study the distribution of the sample. A paired $t$ test was performed to verify whether there were statistically significant differences between the right and left side, and on what side the highest values are found.

An independent two-sample $t$ test was also performed to verify whether statistically significant differences existed between the two sexes and to be able to calculate classification intervals and classification functions in the talus and radius for each of the volumes. The classification intervals are obtained by the exhaustive Chi-Square Automatic Interactive detector method where data are separated in intervals on the basis of the best predictor of the dependent variable (sex). Several intervals are calculated in each operation before the most significant is selected. They are useful to observe what percentage of the males and females in this study sample is distributed among the different intervals. The classification functions are calculated using Fisher's coefficients. A group of coefficients is obtained for each group, and each case is classified on the group where it has the highest discriminant punctuation. They offer the possibility to classify sex giving a correct classification percentage based on the study sample.

Finally, a validation test including all classification functions was performed on a sample of 20 individuals (10 males and 10 females) taken from another contemporary Spanish reference collection (twentieth century; EML 2) also located at the School of Legal Medicine of Madrid and formed by 88 individuals (63 males, 23 females, and 2 unknown) born between the years 1941 and 1976 and died in 1996.

\section{Results}

The results of the descriptive analysis of the sample are shown in Table 2. For all of the variables, the mean values are higher in males than in females, though there is an overlapping range in which both sexes can be found.

The hypothesis that the sample did not follow a normal distribution was rejected because of the results obtained on the Kolmogórov-Smirnov test $(p>0.05)$. Parametric tests were then performed.

There were no statistically significant differences between the volumes calculated from the 3D image repetition process of a sample of 20 tali and 20 radii and the ones calculated first (tali, mean $=0.03, t=0.815, p=0.425 /$ radii, mean $=-0.344, t=-1.242, p=0.229$ ).

There were no statistically significant differences $(p>0.05)$ between the two measures taken on each anatomical region so the mean of both was calculated to minimize the possible errors. No statistically significant differences were found between the two measures taken by the second observer $(p>0.05)$, and no statistically significant differences were found between observers when comparing the volumes calculated on the different anatomical regions on a sample of 20 tali and 20 radii (Table 3).

In the case of females, the paired $t$ test shows that there are statistically significant differences depending upon side for the anterior volume 1, the total volume of the radius, the volume of the diaphysis, and the volume of the distal end, with the values for the right side being greater. In the case of males, there are statistically significant differences depending on side for the anterior volume 1 , the total volume of the radius, and the volume of the diaphysis, with the values for the right side being greater. Because differences have been found depending upon side for some of the variables, the data are presented with differentiation between the right side and left side.

The independent two-sample $t$ test shows statistically significant differences for each of the variables depending upon sex, with the values for males being greater. These differences make it possible to create intervals and classification functions.

The classification intervals determine a series of optimal intervals on the basis of which the sample is classified. The results for the talus are shown in Table 4, and the results for the radius in Table 5 .

The classification functions are shown in Tables 6 and 7, thereby complementing the results of the classification intervals and making possible to determine sex adding a rate of accurate classification. For the talus, classification functions for total volume have been obtained which accurately classify $90.1 \%$ of the sample for the right talus and $90.9 \%$ for the left talus. The total volume is the variable which offers a higher correct classification percentage, followed by the posterior volume.

For the radius, classification functions for total volume have been obtained which accurately classify $93.9 \%$ of the sample for the right radius and $91.8 \%$ for the left radius. These results indicate that radius volume is a good discriminant for sex and that sex can be determined with a high degree of reliability, exceeding the results achieved with the talus. The discriminant power of the head is less than that of total volume, but it must be taken into account in those cases in which one only has this region of the bone available. 
Table 2 Differences between observers

\begin{tabular}{|c|c|c|c|c|c|c|c|}
\hline \multirow[b]{2}{*}{$\begin{array}{l}\text { Observer } \\
2-1\end{array}$} & \multicolumn{4}{|c|}{ Talus, $n=20$} & \multicolumn{3}{|c|}{ Radius, $n=20$} \\
\hline & $\begin{array}{l}\text { Anterior } \\
\text { volume } 1\end{array}$ & $\begin{array}{l}\text { Anterior } \\
\text { volume } 2\end{array}$ & $\begin{array}{l}\text { Anterior } \\
\text { volume } 3\end{array}$ & $\begin{array}{l}\text { Posterior } \\
\text { volume }\end{array}$ & $\begin{array}{l}\text { Head } \\
\text { volume }\end{array}$ & $\begin{array}{l}\text { Diaphysis } \\
\text { volume }\end{array}$ & $\begin{array}{l}\text { Distal end } \\
\text { volume }\end{array}$ \\
\hline Mean & -0.054 & -0.223 & -0.004 & 0.082 & 0.036 & 0.022 & -0.058 \\
\hline$t$ & -0.524 & -1.668 & -0.064 & 0.553 & 1.087 & 0.203 & -0.642 \\
\hline$p$ & 0.606 & 0.112 & 0.95 & 0.586 & 0.291 & 0.841 & 0.529 \\
\hline
\end{tabular}

The diaphysis volume and the distal end volume of the right radius appear to be especially dimorphic offering classification functions that accurately classify 96.9 and $95.5 \%$ of the sample, respectively.

The results obtained on the validation test performed on a sample of 20 individuals (10 males and 10 females) from another Spanish reference collection (EML 2) are shown in Table 8 . The percentage of individuals correctly classified is given for each variable, obtaining the same results for the right and left side.

\section{Discussion}

The talus and radius bones in the postcranial skeleton were selected to verify the discriminant power of the variable of volume. When bone remains are recovered, the pelvis and cranium are not always available for study, though their morphological study makes it possible to determine sex with a high rate of reliability. New studies on bones in the postcranial skeleton are necessary to verify the percentage of accurate classification which can be achieved on the basis of the study variables, taking into account both the bone in its entirety and in part, because bones are not always recovered in the best state of preservation.

$3 \mathrm{D}$ scanning of the sample makes it possible to obtain a reproduction of the bone, which can be accessed from any location and through which many measurements can be taken. As a whole, they constitute a digital library of great value that includes a digitized copy of the original sample which is very useful if the original is lost or deteriorates.
Table 3 Statistics describing the talus and radius volumes (cubic centimeter) in males and females and side differences
${ }^{a}$ Level of significance of the paired $t$ test to study side-based differences

$* p<0.05 ; * * p<0.01$

\begin{tabular}{|c|c|c|c|c|c|c|c|c|c|}
\hline & \multirow[b]{2}{*}{ Side } & \multicolumn{4}{|c|}{ Male } & \multicolumn{4}{|c|}{ Female } \\
\hline & & $N$ & Mean & $\mathrm{SD}$ & $p^{\mathrm{a}}$ & $N$ & Mean & $\mathrm{SD}$ & $p^{\mathrm{a}}$ \\
\hline \multicolumn{10}{|l|}{ Talus } \\
\hline Total volume & $\begin{array}{l}\mathrm{R} \\
\mathrm{L}\end{array}$ & $\begin{array}{l}45 \\
40\end{array}$ & $\begin{array}{l}32.90 \\
32.80\end{array}$ & $\begin{array}{l}4.70 \\
4.33\end{array}$ & 0.18 & $\begin{array}{l}46 \\
48\end{array}$ & $\begin{array}{l}22.77 \\
22.80\end{array}$ & $\begin{array}{l}2.99 \\
3.28\end{array}$ & 0.32 \\
\hline Anterior volume 1 & $\begin{array}{l}\mathrm{R} \\
\mathrm{L}\end{array}$ & $\begin{array}{l}45 \\
40\end{array}$ & $\begin{array}{l}6.83 \\
6.44\end{array}$ & $\begin{array}{l}1.19 \\
1.09\end{array}$ & $0.004 *$ & $\begin{array}{l}46 \\
48\end{array}$ & $\begin{array}{l}4.78 \\
4.58\end{array}$ & $\begin{array}{l}.71 \\
.71\end{array}$ & $0.01 *$ \\
\hline Anterior volume 2 & $\begin{array}{l}\mathrm{R} \\
\mathrm{L}\end{array}$ & $\begin{array}{l}45 \\
40\end{array}$ & $\begin{array}{l}10.27 \\
10.06\end{array}$ & $\begin{array}{l}1.86 \\
1.41\end{array}$ & 0.44 & $\begin{array}{l}46 \\
48\end{array}$ & $\begin{array}{l}7.26 \\
7.24\end{array}$ & $\begin{array}{l}1.05 \\
1.09\end{array}$ & 0.80 \\
\hline Anterior volume 3 & $\begin{array}{l}\mathrm{R} \\
\mathrm{L}\end{array}$ & $\begin{array}{l}45 \\
40\end{array}$ & $\begin{array}{l}6.62 \\
6.48\end{array}$ & $\begin{array}{l}1.55 \\
1.28\end{array}$ & 0.61 & $\begin{array}{l}46 \\
48\end{array}$ & $\begin{array}{l}4.68 \\
4.68\end{array}$ & $\begin{array}{r}.94 \\
1.05\end{array}$ & 0.61 \\
\hline Posterior volume & $\begin{array}{l}\mathrm{R} \\
\mathrm{L}\end{array}$ & $\begin{array}{l}45 \\
40\end{array}$ & $\begin{array}{l}19.28 \\
19.61\end{array}$ & $\begin{array}{l}2.84 \\
2.78\end{array}$ & 0.1 & $\begin{array}{l}46 \\
48\end{array}$ & $\begin{array}{l}13.15 \\
13.22\end{array}$ & $\begin{array}{l}1.87 \\
2.05\end{array}$ & 0.92 \\
\hline \multicolumn{10}{|l|}{ Radius } \\
\hline Total volume & $\begin{array}{l}\mathrm{R} \\
\mathrm{L}\end{array}$ & $\begin{array}{l}32 \\
30\end{array}$ & $\begin{array}{l}42.15 \\
40.92\end{array}$ & $\begin{array}{l}5.61 \\
5.78\end{array}$ & $0.03 *$ & $\begin{array}{l}31 \\
33\end{array}$ & $\begin{array}{l}26.7 \\
26.24\end{array}$ & $\begin{array}{l}4.07 \\
4.49\end{array}$ & $0.002 * *$ \\
\hline Head volume & $\begin{array}{l}\mathrm{R} \\
\mathrm{L}\end{array}$ & $\begin{array}{l}32 \\
30\end{array}$ & $\begin{array}{l}3.38 \\
3.35\end{array}$ & $\begin{array}{l}0.72 \\
0.75\end{array}$ & 0.07 & $\begin{array}{l}31 \\
32\end{array}$ & $\begin{array}{l}2.23 \\
2.19\end{array}$ & $\begin{array}{l}0.48 \\
0.52\end{array}$ & 0.94 \\
\hline Diaphysis volume & $\begin{array}{l}\mathrm{R} \\
\mathrm{L}\end{array}$ & $\begin{array}{l}32 \\
30\end{array}$ & $\begin{array}{l}29.03 \\
28.12\end{array}$ & $\begin{array}{l}3.17 \\
3.83\end{array}$ & $0.006^{* *}$ & $\begin{array}{l}31 \\
33\end{array}$ & $\begin{array}{l}17.86 \\
17.75\end{array}$ & $\begin{array}{l}2.97 \\
3.13\end{array}$ & $0.007 * *$ \\
\hline Distal end volume & $\begin{array}{l}\mathrm{R} \\
\mathrm{L}\end{array}$ & $\begin{array}{l}32 \\
30\end{array}$ & $\begin{array}{l}9.74 \\
9.43\end{array}$ & $\begin{array}{l}1.54 \\
1.59\end{array}$ & 0.51 & $\begin{array}{l}31 \\
33\end{array}$ & $\begin{array}{l}6.46 \\
6.29\end{array}$ & $\begin{array}{l}0.98 \\
1.22\end{array}$ & $0.000 * *$ \\
\hline
\end{tabular}


Table 4 Classification intervals for talus volumes (cubic centimeter)

\begin{tabular}{|c|c|c|c|c|}
\hline Talus & Side & Classification interval & $\% \mathrm{M}^{\mathrm{a}}$ & $\% \mathrm{~F}^{\mathrm{b}}$ \\
\hline \multirow[t]{6}{*}{ Total volume } & \multirow[t]{3}{*}{$\mathrm{R}$} & $\leq 24.921$ & 2.8 & 97.2 \\
\hline & & (24.921-29.676) & 47.4 & 52.6 \\
\hline & & $>29.676$ & 97.2 & 2.8 \\
\hline & \multirow[t]{3}{*}{$\mathrm{L}$} & $\leq 24.129$ & 0 & 100 \\
\hline & & $(24.129-28,526)$ & 38.9 & 61.1 \\
\hline & & $>28,526$ & 94.3 & 5.7 \\
\hline \multirow[t]{6}{*}{ Anterior volume 1} & \multirow[t]{4}{*}{$\mathrm{R}$} & $\leq 4.76$ & 3.7 & 96.3 \\
\hline & & $(4.76-5.135)$ & 44.4 & 55.6 \\
\hline & & $(5.135-5.82)$ & 31.58 & 68.42 \\
\hline & & $>5.82$ & 94.4 & 5.6 \\
\hline & \multirow[t]{2}{*}{$\mathrm{L}$} & $\leq 5.52$ & 13.2 & 86.8 \\
\hline & & $>5.52$ & 94.3 & 5.7 \\
\hline \multirow[t]{4}{*}{ Anterior volume 2} & \multirow[t]{2}{*}{$\mathrm{R}$} & $\leq 8.31$ & 11.1 & 88.9 \\
\hline & & $>8.31$ & 87 & 13 \\
\hline & \multirow[t]{2}{*}{$\mathrm{L}$} & $\leq 8.232$ & 6.8 & 93.2 \\
\hline & & $>8.232$ & 84.1 & 15.9 \\
\hline \multirow[t]{6}{*}{ Anterior volume 3} & \multirow[t]{3}{*}{$\mathrm{R}$} & $\leq 5.123$ & 11.1 & 88.9 \\
\hline & & $(5.123-5.805)$ & 47.4 & 52.6 \\
\hline & & $>5.805$ & 88.9 & 11.1 \\
\hline & \multirow[t]{3}{*}{$\mathrm{L}$} & $\leq 4.96$ & 5.7 & 94.3 \\
\hline & & $(4.96-5.594)$ & 50 & 50 \\
\hline & & $>5.594$ & 82.9 & 17.1 \\
\hline \multirow[t]{5}{*}{ Posterior volume } & \multirow[t]{3}{*}{$\mathrm{R}$} & $\leq 13.130$ & 0 & 100 \\
\hline & & (13.130-17.265) & 32.1 & 67.9 \\
\hline & & $>17.265$ & 100 & 0 \\
\hline & \multirow[t]{2}{*}{$\mathrm{L}$} & $\leq 16.02$ & 2.3 & 97.7 \\
\hline & & $>16.02$ & 88.6 & 11.4 \\
\hline
\end{tabular}

${ }^{\text {a }}$ Percentage of males on each interval

${ }^{\mathrm{b}}$ Percentage of females on each interval

One must bear in mind the limitations of these techniques when they are used because, among other issues, the image quality is conditional upon the scanning quality, which in turn depends upon the scanner and the selection of parameters performed by the professional when scanning the bone. Although no statistically significant differences have been found during the merging and the image processing, it is important to do these steps with the maximum possible precision. The fact that no statistically significant differences have been found between the two measures performed on the different anatomical regions and between observers confirms that there is a low variability performing the divisions, but it is necessary to take precautions with the orientation of the bone and the positioning of the points to minimize errors. The results obtained show a high level of discriminant power for the variable of
Table 5 Classification intervals for radius volumes (cubic centimeter)

\begin{tabular}{|c|c|c|c|c|}
\hline Radius & Side & Classification interval & $\% \mathrm{M}^{\mathrm{a}}$ & $\% \mathrm{~F}^{\mathrm{b}}$ \\
\hline \multirow[t]{4}{*}{ Total volume } & \multirow[t]{2}{*}{$\mathrm{R}$} & $\leq 32.661$ & 0 & 100 \\
\hline & & $>32.661$ & 97 & 3 \\
\hline & \multirow[t]{2}{*}{$\mathrm{L}$} & $\leq 32.500$ & 3.3 & 96.7 \\
\hline & & $>32.500$ & 93.5 & 6.5 \\
\hline \multirow[t]{5}{*}{ Head volume } & \multirow[t]{2}{*}{$\mathrm{R}$} & $\leq 2.648$ & 12.5 & 87.5 \\
\hline & & $>2.648$ & 84.8 & 15.2 \\
\hline & \multirow[t]{3}{*}{$\mathrm{L}$} & $\leq 1.941$ & 0 & 100 \\
\hline & & $(1.941-2.816)$ & 36 & 64 \\
\hline & & $>2.816$ & 87.5 & 12.5 \\
\hline \multirow[t]{5}{*}{ Diaphysis volume } & \multirow[t]{2}{*}{$\mathrm{R}$} & $\leq 22.884$ & 0 & 100 \\
\hline & & $>22.884$ & 97 & 3 \\
\hline & \multirow[t]{3}{*}{$\mathrm{L}$} & $\leq 20.494$ & 0 & 100 \\
\hline & & (20.494-24.397) & 46.2 & 53.8 \\
\hline & & $>24.397$ & 100 & 0 \\
\hline \multirow[t]{4}{*}{ Distal end volume } & \multirow[t]{2}{*}{$\mathrm{R}$} & $\leq 7.498$ & 6.1 & 93.9 \\
\hline & & $>7.498$ & 93.9 & 6.1 \\
\hline & \multirow[t]{2}{*}{$\mathrm{L}$} & $\leq 7.478$ & 10 & 90 \\
\hline & & $>7.478$ & 87.1 & 12.9 \\
\hline
\end{tabular}

${ }^{\text {a }}$ Percentage of males on each interval

${ }^{\mathrm{b}}$ Percentage of females on each interval

volume in the talus and radius, with the ability to accurately classify from 90.9 to $96.9 \%$ of the sample, the best results having been found using the radius.

Table 6 Classification functions for talus volumes (cubic centimeter)

\begin{tabular}{|c|c|c|c|}
\hline Talus & Side & Classification function & $\% \mathrm{CC}^{\mathrm{a}}$ \\
\hline \multirow[t]{2}{*}{ Total volume } & $\mathrm{R}$ & $\begin{array}{l}0.656(\mathrm{vol})-18.271>0 \text { male } \\
<0 \text { female }\end{array}$ & 90.1 \\
\hline & $\mathrm{L}$ & $\begin{array}{l}0.694(\mathrm{vol})-19.302>0 \text { male } \\
<0 \text { female }\end{array}$ & 90.9 \\
\hline \multirow[t]{2}{*}{ Anterior volume 1} & $\mathrm{R}$ & $\begin{array}{l}2.127(\mathrm{vol})-12.346>0 \text { male } \\
<0 \text { female }\end{array}$ & 86.8 \\
\hline & $\mathrm{L}$ & $\begin{array}{l}2.279 \text { (vol) }-12.563>0 \text { male } \\
<0 \text { female }\end{array}$ & 88.6 \\
\hline \multirow[t]{2}{*}{ Anterior volume 2} & $\mathrm{R}$ & $\begin{array}{l}1.323(\mathrm{vol})-11.601>0 \text { male } \\
<0 \text { female }\end{array}$ & 85.7 \\
\hline & $\mathrm{L}$ & $\begin{array}{l}1.828(\mathrm{vol})-15.824>0 \text { male } \\
<0 \text { female }\end{array}$ & 89.8 \\
\hline \multirow[t]{2}{*}{ Anterior volume 3} & $\mathrm{R}$ & $\begin{array}{l}1.175(\mathrm{vol})-6.640>0 \text { male } \\
<0 \text { female }\end{array}$ & 80.2 \\
\hline & $\mathrm{L}$ & $\begin{array}{l}1.348(\text { vol })-7.522>0 \text { male } \\
<0 \text { female }\end{array}$ & 79.5 \\
\hline \multirow[t]{2}{*}{ Posterior volume } & $\mathrm{R}$ & $\begin{array}{l}1.064(\mathrm{vol})-17.249>0 \text { male } \\
<0 \text { female }\end{array}$ & 89 \\
\hline & $\mathrm{L}$ & $\begin{array}{l}1.098(\text { vol })-18.025>0 \text { male } \\
<0 \text { female }\end{array}$ & 89.8 \\
\hline
\end{tabular}

${ }^{\mathrm{a}}$ Percentage of correct classified 
Table 7 Classification functions for radius volumes (cubic centimeter)

\begin{tabular}{|c|c|c|c|}
\hline Radius & Side & Classification function & $\% \mathrm{CC}^{\mathrm{a}}$ \\
\hline \multirow[t]{2}{*}{ Total volume } & $\mathrm{R}$ & $\begin{array}{l}0.650(\mathrm{vol})-22.376>0 \text { male } \\
<0 \text { female }\end{array}$ & 93.9 \\
\hline & $\mathrm{L}$ & $\begin{array}{l}0.549(\mathrm{vol})-18.458>0 \text { male } \\
<0 \text { female }\end{array}$ & 91.8 \\
\hline \multirow[t]{2}{*}{ Head volume } & $\mathrm{R}$ & $\begin{array}{l}3.072(\mathrm{vol})-8.616>0 \text { male } \\
<0 \text { female }\end{array}$ & 76.9 \\
\hline & $\mathrm{L}$ & $\begin{array}{l}2.808(\mathrm{vol})-7.78>0 \text { male } \\
<0 \text { female }\end{array}$ & 80.3 \\
\hline \multirow[t]{2}{*}{ Diaphysis volume } & $\mathrm{R}$ & $\begin{array}{l}0.975(\mathrm{vol})-22.873>0 \text { male } \\
<0 \text { female }\end{array}$ & 96.9 \\
\hline & $\mathrm{L}$ & $\begin{array}{l}0.85(\text { vol })-19.512>0 \text { male } \\
<0 \text { female }\end{array}$ & 91.8 \\
\hline \multirow[t]{2}{*}{ Distal end volume } & $\mathrm{R}$ & $\begin{array}{l}1.976(\mathrm{vol})-16.003>0 \text { male } \\
<0 \text { female }\end{array}$ & 95.5 \\
\hline & $\mathrm{L}$ & $\begin{array}{l}1.564(\mathrm{vol})-12.296>0 \text { male } \\
<0 \text { female }\end{array}$ & 88.5 \\
\hline
\end{tabular}

${ }^{\text {a }}$ Percentage of correct classified

The discriminant power of the anterior region of the talus is lower than that provided by total volume, but it would be useful in those cases in which the bone is incomplete and this region is well preserved. In the event that only the anterior region of the talus bone is available, an accurate classification can be achieved for 79.5 to $89.8 \%$ of the sample. In such cases, it is recommendable to consult the classification intervals to verify whether the volume calculated falls within an overlapping range or whether, on the contrary, the volume has a value for which there are only representatives of one of the two sexes.

As for the radius, the distal end turned out to be more discriminant that the proximal end, achieving an accurate classification of $95.5 \%$ of the sample. The diaphysis in the right radius has proven to be especially discriminant, given that the highest rate of accurate classifications was found for all of the variables, $96.9 \%$.

Observing the rates of accurate classification which take side into account, one can see that, in the case of the talus, there is hardly any difference between the two sides. However, the differences are more notable in the case of the radius. This coincides with the results found in the paired $t$ test, in which statistically significant differences have been observed $(p<0.05)$ between the two sides for the total volumes, the diaphysis and the distal end of the radius, with the values for the right side being greater. For the talus, better results are obtained for the left side in four of five variables studied, for the radius, with a higher lateral asymmetry, better results are obtained for the right side in three of four variables studied.

The validation test confirms the discriminant power of this variable when applied to a sample from another contemporary Spanish reference collection (EML 2). The classification functions obtained in this study were only confirmed to be reliable for the Spanish population. Later comparative studies with other populations will be necessary to determine the variability between populations. As occurs with the classification functions based on metric variables, in order to be able to apply them to other populations, one must take into account the range of variation, ruling out their use in those cases in which the range of variability for each sex is different than that of the study sample herein.

\section{Conclusions}

In 3D scanning of bone, special attention must be paid to the selection of parameters, the image's processing, and the selection of anatomical divisions performed on the bone. From the results found, it can be concluded that the variable of volume is a good discriminant of sex in this study sample, accurately determining sex in $90.9 \%$ of all cases, on the basis of the total volume of the left talus, and $93.9 \%$ when using the total volume of the right radius. By calculating the volume in different anatomical regions, the diaphysis of the right radius has demonstrated a high discriminant power $(\mathrm{CC}=96.9 \%)$ as well as the distal end $(\mathrm{CC}=95.5 \%)$ both discriminating better than the total volume. The results found provide a reason to continue researching the discriminant power of this variable in other bones of the postcranial skeleton and calculate classification

Table 8 Validation test

\begin{tabular}{llllll}
\hline Talus & Total volume & Anterior volume 1 & Anterior volume 2 & Anterior volume 3 & Posterior volume \\
CC & $90 \%$ & $80 \%$ & $85 \%$ & $90 \%$ & $90 \%$ \\
Radius & Total volume & Head volume & Diaphysis volume & Distal end volume \\
CC & $95 \%$ & $80 \%$ & $95 \%$ & $90 \%$ & \\
\hline
\end{tabular}

$C C$ percentage of individuals correctly classified with each variable 
functions which can be used on the Spanish population to determine sex in a reliable manner.

Acknowledgments We thank the Computer Center of Universidad Complutense de Madrid for the availability of the 3D scanner, and we specially thank Pedro Cuesta Álvaro for the revision of the statistical study.

\section{References}

1. Steel DG (1976) The estimation of sex on the basis of the talus and calcaneus. Am J Phys Anthropol 45:581-588

2. Gualdi-Russo E (2007) Sex determination from the talus and calcaneus measurements. Forensic Sci Int 17:151-156

3. Berrizbeitia EL (1989) Sex determination with the head of the radius. J Forensic Sci 34(5):1206-1213

4. Barrier ILO, L'Abbé EN (2008) Sex determination from the radius and ulna in a modern South African sample. Forensic Sci Int 179:85.e1-85.e7

5. Machado-Mendoza D, Pablo-Pozo J (2008) Estudio del dimorfismo sexual del radio en europoides cubanos. Rev Esp Antropol Fís 28:81-86

6. Singh S, Singh SP (1975) Identification of sex from tarsal bones. Acta Anat 93:568-573

7. Todd TW, Kuenzel W (1925) The estimation of cranial capacity: a comparison of the direct water and seed methods. Am J Phys Anthropol 8(3):251-259

8. Stewart TD (1934) Cranial capacity studies. Am J Phys Anthropol 23(3):337-361

9. Uspenskii S (1954) A new method for measuring cranial capacity. Am J Phys Anthropol 22:115-117

10. Mackinnon L, Kennedy JA, Davies TV (1956) Estimation of skull capacity from roentgenologic measurements. Am J Roentgenol Radium Ther Nucl Med 76(2):303-310

11. Jorgensen JB, Quaade F (1956) The external cranial volume as an estimate of cranial capacity. Am J Phys Anthropol 14(4):661-664

12. Kaufman B, David CJ (1972) A method of infracranial volume calculation. Invest Radiol 7:533-538

13. Olivier G, Tissier H (1975) Determination of cranial capacity in fossil men. Am J Phys Anthropol 43(3):353-362

14. Mayhew TM, Olsen DR (1991) Magnetic resonance imaging (MRI) and model-fore brain estimates of forebrain volume determined using the Cavalieri principle. J Anat 178:133-144

15. Steven RL (1992) Cranial capacity evolution in Homo erectus and early Homo sapiens. Am J Phys Anthropol 87(1):1-13
16. Baab KL, McNulty KP (2008) Size, shape and asymmetry in fossil hominids: the status of the LB1 cranium based on 3D morphometric analyses. J Hum Evol 30:1-15

17. Lorenzo C, Carretero JM, Arsuaga JL, Gracia A, Martínez I (1998) Intrapopulational body size variation and cranial capacity variation in Middle Pleistocene humans: the Sima de los Huesos sample (Sierra de Atapuerca, Spain). Am J Phys Anthropol 106(1):19-33

18. Butaric LN, McCarthy RC, Broadfild DC (2010) A preliminary 3D computed tomography study of the human maxillary sinus and nasal cavity. Am J Phys Anthropol 143(3):426-436

19. Allen JS, Damasio H, Grabowski TJ (2002) Normal neuroanatomical variation in the human brain: An MRI-volumetric study. Am J Phys Anthropol 118(4):341-358

20. Craig JG, Cody DD, Van Holsbeeck M (2004) The distal femoral and proximal tibial growth plates: MR imaging, three-dimensional modeling and estimation of area and volume. Skeletal Radiol 33:337-344

21. Cicuttini F, Forbes A, Morris K, Darling S, Bailey M, Stuckey S (1999) Gender differences in knee cartilage volume as measured by magnetic resonance imaging. Osteoarthr Cart 7:265-271

22. Faber SC, Eckstein F, Lukasz S, Muhlbauer R, Hohe J, Englmeier KH, Reiser M (2001) Gender differences in knee joint cartilage thickness, volume and articular surface areas: assessment with quantitative three-dimensional MR imaging. Skeletal Radiol 30:144-150

23. Kranioti EF, Nathena D, Michalodimitrakis M (2011) Sex estimation of the Cretan humerus: a digital radiometric study. Int J Legal Med 125:659-667

24. Hsiao TH, Tsai SM, Chou ST, Pan JY, Tseng YC, Chang HP, Chen HS (2010) Sex determination using discriminant function analysis in children and adolescents: a lateral cephalometric study. Int J Legal Med 124:155-160

25. Macalauso PJ (2011) Sex discrimination from the glenoid cavity in black South Africans: morphometric analysis of digital photographs. Int J Legal Med 125:773-778

26. Sholts SB, Wärmländer S, Flores LM, Miller K, Walker PL (2010) Variation in the measurement of cranial volume and surface area using 3D laser scanning technology. J Forensic Sci 55(4):871-875

27. Pretorius E, Steyn M, Scholtz Y (2006) Investigation into the usability of geometric morphometric analysis in assessment of sexual dimorphism. Am J Phys Anthropol 129:64-70

28. Bytheway JA, Ross AH (2010) A geometric morphometric approach to sex determination of the human adult os coxa. J Forensic Sci 55(4):859-864

29. Giancoli DC (1997) Física, principios con aplicaciones. Prentice Hall, Upper Saddle River 